\title{
InGaAs/AlGaAs Quantum Wire DFB Laser by One-Time Selective MOCVD on Ridge Substrate
}

\author{
Yasuyuki Takasuka Member ( Shibaura Institute of Techonology, y-takasuka@aist.go.jp) \\ Kenji Yonei Member ( Shibaura Institute of Techonology) \\ Mutsuo Ogura Member (National Institute of Advanced Industrial Science and Technology )
}

Keywords : Quantum wire, DFB laser, V-groove grating ridge substrate, one-time selective MOCVD, trapezoidal growth profile

Quantum wires (QWRs) and quantum dots are promising for future optoelectronic devices, because their steep density of states and carrier confinement mechanism result in a large differential gain and a low threshold current. But uniformity and high-density of quantum structures are needed for their primary performance.

Distributed feedback (DFB) laser produced single longitudinal mode by the gratings of the light-waveguide or the active region.

Although it is necessity to form quantum-structures and DFB-structures inside the semiconductor laser, conventional laser needs complex multiple regrowth and etching processes. Multiple regrowth processes induce some problems that increase process-cost, and deteriorate crystal quality.

Figure 1 shows the schematic drawing of InGaAs/AlGaAs quantum wire DFB laser. In this study, we demonstrate a QWR-DFB laser on a ridge substrate with a submicron grating. Here, we used one-time selective MOCVD to form a ridge waveguide with a BH structure and a QWR array for gain-guided

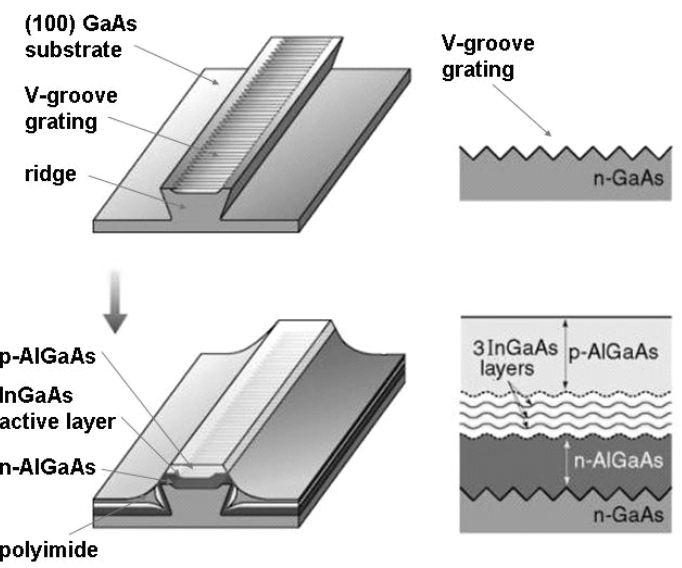

Fig. 1. Schematic drawing of InGaAs/AlGaAs quantum wire DFB laser
DFB LD without additional etching or regrowth process.

A ridge waveguide $\mathrm{LD}$ with a quasi-BH structure was obtained by selective metalorganic chemical vapor deposition (MOCVD). The orientation dependence of crystal growth led to the formation of a trapezoidal cross section with thin sidewalls, and a low-capacitance optical waveguide and a carrier confinement structure were realized at the same time.

Figure 2 shows the spontaneous emission and lasing spectra of the QWR-DFB laser. We observed lasing emission at $811.9 \mathrm{~nm}$ when the current is $14.9 \mathrm{~mA}$. A stable single longitudinal mode was preserved until $3 \mathrm{I}_{\mathrm{th}}$, after which another mode emerged at a high drive current at $813.6 \mathrm{~nm}$. This suggests a complex-coupled DFB-mode operation. The coupled coefficient is estimated to be higher than $67 \mathrm{~cm}^{-1}$ from the wavelength difference between two peaks.

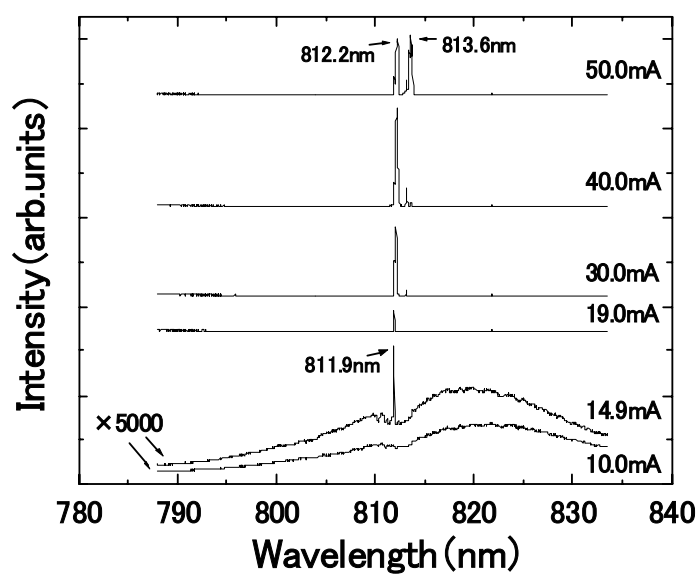

Fig. 2. Spontaneous emission and lasing spectrum of InGaAs/AlGaAs quantum wire DFB laser under pulsed condition 


\title{
リッジ基板上の一回の選択 MOCVD による \\ InGaAs/AlGaAs 量子細線 DFB レーザー
}

\author{
正 員 高須賀庸行* 正 員 米井 健治* \\ 非会員 小倉 睦郎**
}

\section{InGaAs/AlGaAs Quantum Wire DFB Laser by One-Time Selective MOCVD on Ridge Substrate Yasuyuki Takasuka*, Member, Kenji Yonei*, Member, Mutsuo Ogura**, Non-member}

\begin{abstract}
A quasi-buried hetero-structure (BH) quantum wire (QWR) distributed feedback (DFB) laser was realized by one time selective metalorganic chemical vapor deposition (MOCVD) on a ridge substrate with a sub-micron grating. One time selective MOCVD growth forms ridge waveguide with BH structure and a QWR array for gain guided DFB LD without additional etching or re-growth process. The threshold current is $15 \mathrm{~mA}$, and the threshold current density is $850 \mathrm{~A} / \mathrm{cm}^{2}$. A stable single longitudinal mode was preserved until $3 \mathrm{I}_{\mathrm{th}}$, after which another mode emerged at higher drive current at $813.6 \mathrm{~nm}$. This suggests a complex coupled DFB mode operation. Elimination of the re-growth step also enlarges the selection of material for extended wavelength and operational temperature.
\end{abstract}

キーワード：量子細線，分布帰還型レーザー，V 溝グレーティングリッジ基板，一回の選択 MOCVD，台形型成長断面

Keywords : Quantum wire, DFB laser, V-groove grating ridge substrate, one-time selective MOCVD, trapezoidal growth profile

\section{1. はじめに}

光加入者網の整備 (FTTH : fiber to the home) に伴い，イ ンターネットのトラフィックは 2005 年現在, 年率 200-300\% で増加している。長距離・大容量伝送の需要の増加には際 限がないが，加入者レベルに対して普及させるためは，要 求性能を満たす光デバイスを，簡便に製造し，提供するこ とが求められている。

量子ナノ構造は, キャリアの状態密度を急峻にし, 利得 が特定のエネルギー準位に集中する結果，半導体レーザー の発振の低閾值化につながることが理論的に予測され，量 子細線・量子ドットなど量子構造を用いた半導体レーザー が，これまで研究されてきた(1)(2)。しかし量子構造が本来の 特性を発揮するには形状の均一性と高密度性が要求され る。量子ナノ構造の量子レベルの均一性を確保するために は, 1 原子層 $(0.28 \mathrm{~nm})$ レベルでの加工精度が必要になり, 従来のリソグラフィ技術の精度では不十分である。

一方, 長距離・大容量の伝送を行うためには, 光ファイ

* 芝浦工業大学

干135-8548 東京都江東区豊洲 3-7-5

Shibaura Institute of Techonology.,

3-7-5 Toyosu, Koutou-ku, Tokyo 135-8548

** 独立行政法人産業技術総合研究所

干305-8568 茨城県つくば市梅園 1-1-1

National Institute of Advanced Industrial Science and Technology ., 1-1-1 Umezono, Tsukuba-shi, Ibaraki 305-8568
バーの波長分散による光パルスの広がりを避けるため, 単 一波長半導体レーザーが求められる。分布帰還型（DFB： Distributed feedback）レーザーは，光導波路あるいは活性領 域に回折格子を形成するもので, これにより単一モード発 振が得られる。

そこで，このような量子ナノ構造や回折格子を半導体レ 一ザー内に作り込む技術が必要となるが，これまでは，通 常, 複数回の結晶成長と中断・エッチングなどの煩雑なプ ロセスを必要としてきた ${ }^{(3)(4)}$ 。成長中断と再成長プロセス は，製造工程の煩雑化を招くとともに，再成長界面におけ る結晶品質の劣化など様々な問題があった。また，最近は， パッケージに冷却機構を持たない加入者系用の半導体レー ザーとして, InGaAlAs 系材料が着目されているが(5), 従来 の再成長を含む工程では，大気中で容易に酸化されやすい $\mathrm{Al}$ のような材料を用いることは困難であった。このような 複数回の再成長を伴うプロセスが複雑なのは明らかであ り，製造工程の簡素化のため，再成長が不要な作製方法が 新たに望まれる。

そこで我々は，逆メサ構造を持つ $\mathrm{V}$ 溝グレーティング基 板上の一回の選択 MOCVD によって低閯值の InGaAs/AlGaAs 量子細線 DFB レーザーを作製したので，そ れについて報告する。 

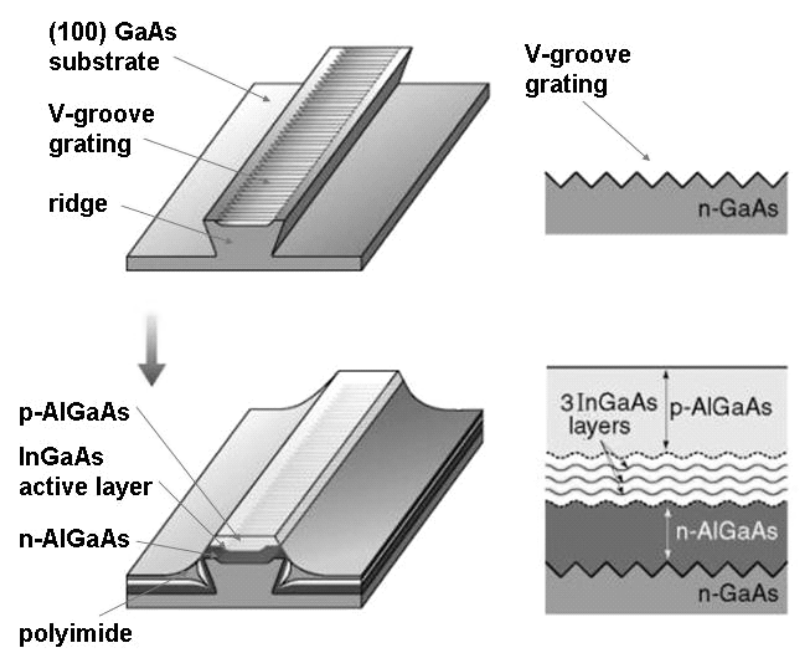

Fig. 1. Schematic drawing of InGaAs/AlGaAs quantum wire DFB laser

\section{2. 研究内容}

図 1 は InGaAs/AlGaAs 量子細線 DFB レーザーの模式図で ある。量子細線構造および DFB 構造を作製するため，まず $\mathrm{GaAs}$ （100）基板に対し V 溝グレーティング形成およびリ ッジ構造形成を行う。次に MOCVD 法によって $\mathrm{Al}_{0.38} \mathrm{GaAs}$ 層を導波路とする $\mathrm{In}_{0.2} \mathrm{GaAs}$ 量子細線層を形成する。その後 絶縁膜形成・電極膜蒸着を行い， へき開してレーザーバー とする。

本研究の結果, $\mathrm{V}$ 溝グレーティングリッジ基板に対する 一回の結晶成長によって, 量子細線構造, DFB 構造, 電流 狭窄構造, 導波路構造など各必要な要素を有するレーザー を，プロセス上問題がある再成長を行うことなしに簡便な プロセスで作製することが可能となる。

\section{3. 作製プロセス}

細線構造および DFB 構造を作製するため，まず基板に対 し電子ビーム描画とウェットエッチングにより V 溝グレー ティング形成を行った。

ここでグレーティング周期と発振波長について考察す る。導波路の屈折率を $n$, DFB グレーティングの周期を $d$ とすると, グレーティング一周期分の光学距離は $n d$ となる。 ブラッグ反射が起こるためには，波長の $1 / 2$ の整数 $(N)$ 倍と $n d$ が等しくなればよい。すなわち，

$$
N \frac{\lambda}{2}=n d
$$

これよりブラッグ波長は

$$
\lambda=\frac{2 n d}{N}
$$

となる。

細線の密度および DFB 効果の点からはなるべくグレーテ イング周期が小さいことが望ましいが，その一方 $1 \mu \mathrm{m}$ 程度 の厚い結晶成長をすると序々に断面形状が崩れ，細線およ

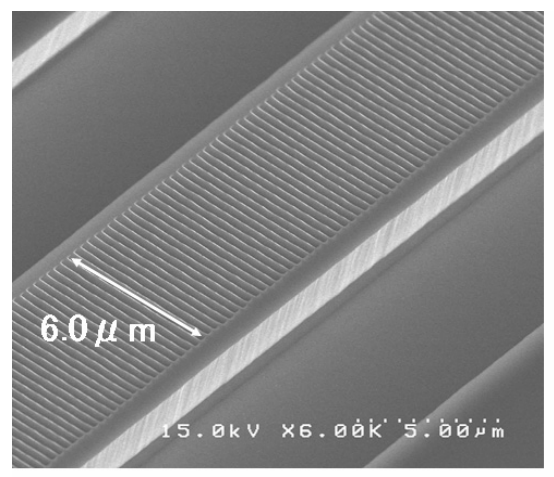

(a)

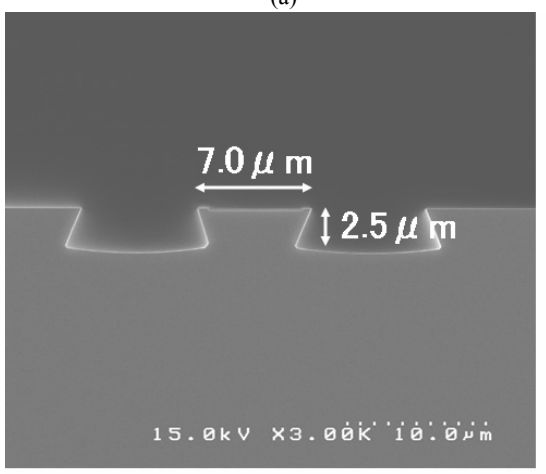

(b)

Fig. 2. SEM image (a), and cross sectional SEM image (b), of InGaAs/AlGaAs quantum wire DFB laser

びDFB 構造を得ることが難しくなる。そこで本研究では次 数 $N=3$, グレーティング周期 $d=360 \mathrm{~nm}$ として試料を作製し た。この場合文献(5)より波長 $810 \mathrm{~nm}$ 帯における $\mathrm{Al}_{0.38} \mathrm{GaAs}$ の屈折率を $n=3.39$ として計算すると, ブラッグ波長は $\lambda=813.6 \mathrm{~nm}$ となる。

また横方向閉じ込めおよび電子ビーム描画時間短縮のた めグレーティング幅は $6 \mu \mathrm{m}$ とした。

結晶の面方位によるエッチング速度の異方性により, 図 1 に示すような V 溝形状が得られる。エッチング液には, GaAs に対して代表的な硫酸一過酸化水素一水 溶液を用いた。

この液は組成によりエッチング速度および断面形状が変 化することが知られているが，本研究では 1:8:40 の液を用 いることにした。

さらに, 同様の液にてリッジ形成を行った。

図 2 にリッジ基板上の $\mathrm{V}$ 溝グレーティングの模式図と SEM 像を示す。

中央の逆台形の上に周期 $360 \mathrm{~nm}$ のV 溝グレーティングが 形成されており，良好な形状の形状基板が作製できたこと がわかる。

図 3 に MOCVD 成長後のリッジストライプに沿った方向 の量子細線 DFB レーザーの断面 TEM 像を示す。

$\mathrm{V}$ 溝 $\mathrm{GaAs}$ 基板上に厚さ約 $1 \mu \mathrm{m}$ の $\mathrm{Al}_{0.38} \mathrm{GaAs}$ 層があり, さらにその上に $\mathrm{In}_{0.2} \mathrm{GaAs}$ 量子細線構造が周期的に形成され ているのがわかる。厚い $\mathrm{Al}_{0.38} \mathrm{GaAs}$ 成長のため $\mathrm{V}$ 溝が鈍角 化し $\mathrm{In}_{0.2} \mathrm{GaAs}$ 量子細線はやや広く伸びた形となっている。 
図 4 は断面 TEM 像の拡大図である。図 4 の縦方向に確認さ れる線状のものはいわゆる垂直量子井戸とよばれるもので あり,これは $\mathrm{V}$ 溝構造によって $\mathrm{Al}_{0.38} \mathrm{GaAs}$ 中の $\mathrm{Al}$ の疎密が 生じるためである。

その後，成長後の試料に対し電極作製プロセスを行った。 熱 CVD により厚さ $120 \mathrm{~nm} の \mathrm{SiO}_{2}$ 薄膜を形成し，BHF エッ チングにより幅 $3.5 \mu \mathrm{m}$ のストライプ空を開口した。そのと きポリイミド塗布およびアッシングにより試料のリッジ側 面部分を平坦化した。試料表面に $\mathrm{p}$ 電極として $\mathrm{Cr} / \mathrm{Au}$ を $30 \mathrm{~nm} / 200 \mathrm{~nm}$, 試料裏面に $\mathrm{n}$ 電極として $\mathrm{AuGe} / \mathrm{Ni} / \mathrm{Au}$ を $100 \mathrm{~nm} / 80 \mathrm{~nm} / 200 \mathrm{~nm}$ 真空蒸着し, それぞれ $430^{\circ} \mathrm{C}$ と $440^{\circ} \mathrm{C}$ で アロイを行った。最後に, $500 \mu \mathrm{m}$ と $4 \mathrm{~mm}$ のレーザーバーに 加工した。両端面にコートは施していない。

\section{4. 作製後の試料}

図 5 は試料の [0-1-1] 方向の断面 SEM である。元々あっ た逆メサ型断面の上に，厚さ $2 \mu \mathrm{m}$ の成長がなされている。 形状基板上の成長により，自己形成的に台形型成長断面が 得られていることがわかる。図 6 は断面 SEM の拡大図であ る。斜面において成長が起こらず $\mathrm{p}-\mathrm{AlGaAs}$ 層が分断されて いるのがわかる。そのため，横方向への電流が遮断され電 流狭窄が可能となる。

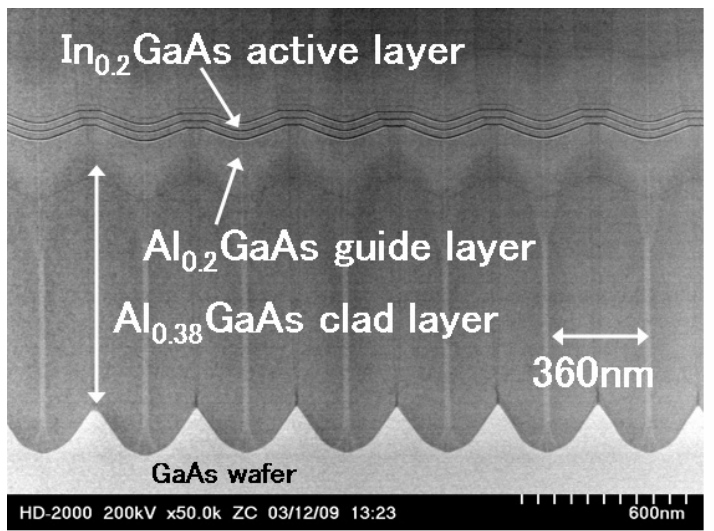

Fig. 3. Cross-sectional TEM image of quantum wire DFB laser along ridge stripe

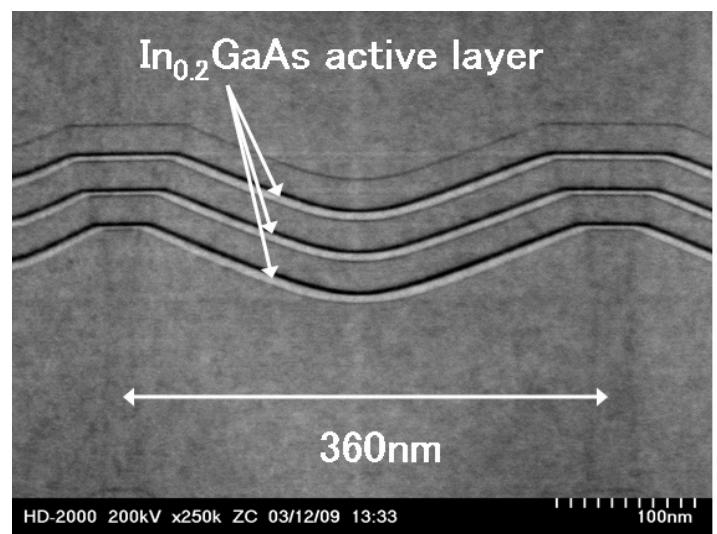

Fig. 4. Enlarged cross-sectional TEM image of quantum wire DFB laser along ridge stripe
図 7 に $30 \mathrm{~mA}$ 注入時のレーザーダイオードのニアフィー ルドパターンを示す。両脇の側面が非常に薄いため，注入 された電流が有効に試料中央のリッジ部分に集中されてい るのがわかる。これによって本研究で意図した自己形成的 な電流狭窄・導波路構造が実際に作製されていることが確 認できた。

\section{5. 測定結果}

作製した InGaAs/AlGaAs 量子細線 DFB レーザーについ

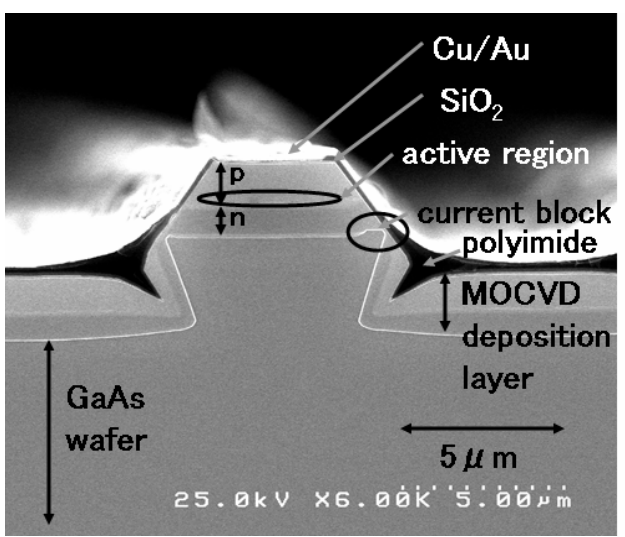

Fig. 5. Cross-sectional SEM image of quantum wire DFB laser across ridge stripe

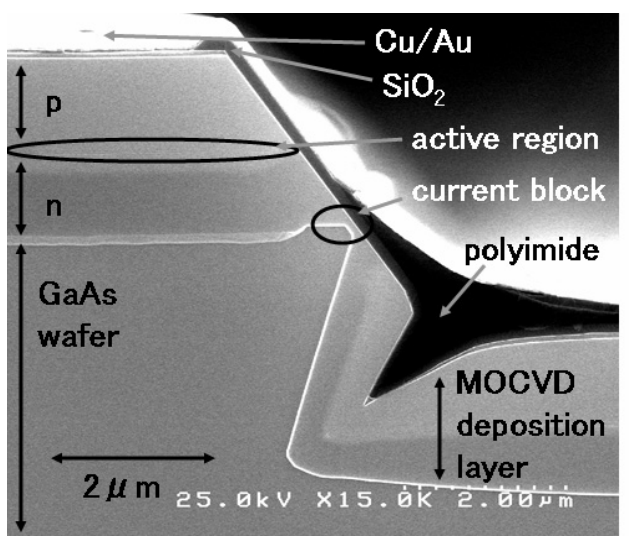

Fig. 6. Enlarged cross-sectional SEM image of quantum wire DFB laser across ridge stripe

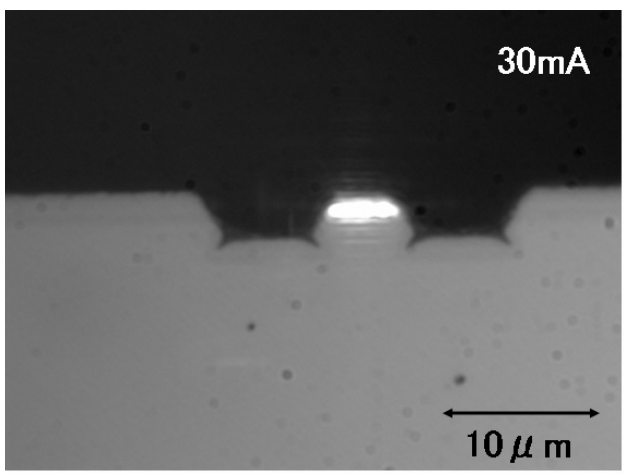

Fig. 7. Near-field pattern of laser diode after being planarized using polyimide 
て, 室温においてパルス電流注入によりその特性を評価し た。以下にその結果を示す。

図 8 に, 本 InGaAs/AlGaAs 量子細線 DFB レーザーの, 室 温におけるパルス電流注入下での電流対光出力特性を示 す。電流值がおよそ $30 \mathrm{~mA}$ 以上で光出力が急速に増大して いる。閾值電流は $15 \mathrm{~mA}$, 閾值電流密度は $850 \mathrm{~A} / \mathrm{cm}^{2}$ である。 またこの IL 特性より求められる微分量子効率は $0.029 \mathrm{~W} / \mathrm{A}$ である。

図 9 に量子細線 DFB レーザーの自然放出および発振スペ クトルを示す。電流值 $14.9 \mathrm{~mA}$ のときに波長 $811.9 \mathrm{~nm}$ のレー ザー発振が得られ，これは先の計算によるブラッグ波長の 值 813.6nm とよく一致している。安定な単一縦モードが閾 值の 3 倍程度まで保持され, その後, 高電流駆動時に波長 813.6nm において別のモードが現れた。これは複素結合 DFB モードを表していると考えられる。2つの波長間隔から結合 係数は $67 \mathrm{~cm}^{-1}$ と見積もられる。

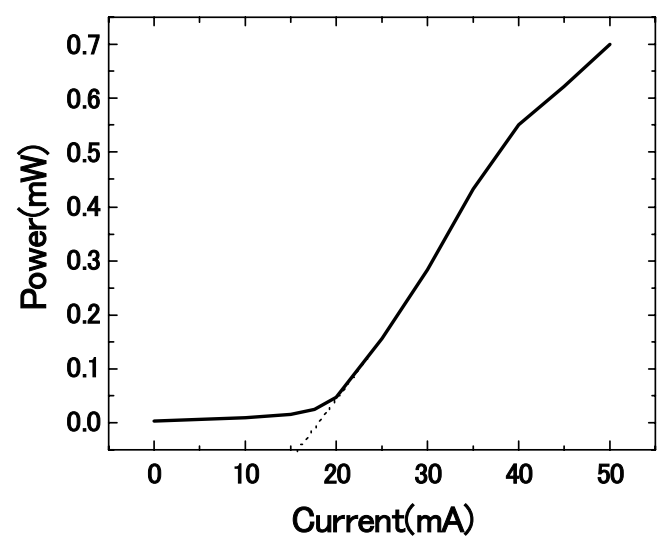

Fig. 8. Current vs. light output characteristics of InGaAs/AlGaAs quantum wire DFB laser under pulsed condition

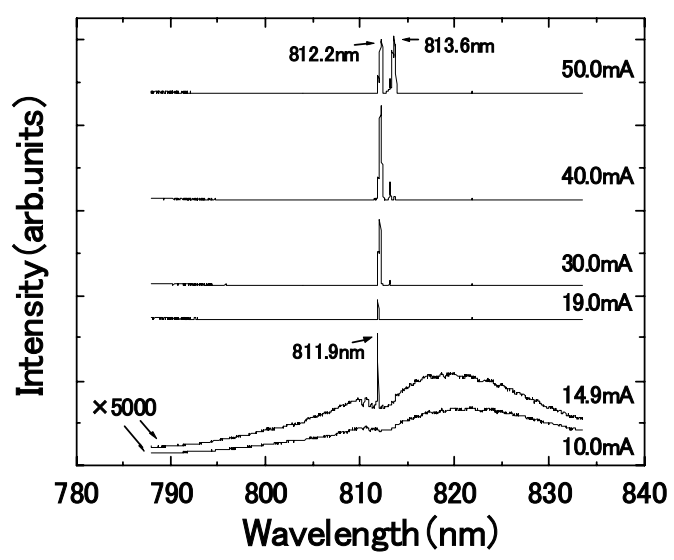

Fig. 9. Spontaneous emission and lasing spectrum of InGaAs/AlGaAs quantum wire DFB laser under pulsed condition

\section{6. 結 論}

逆メサ構造を持つ $\mathrm{V}$ 溝グレーティング基板上の一回の選 択 MOCVD によって, 低閾值の InGaAs/AlGaAs 量子細線 DFB レーザーを作製した。これによって半導体レーザーに 必要な全ての構造を，より簡素に作製できるようになった。 成長速度の方位依存性により台形型断面が形成・電流経 路が分断され, 実際に電流狭窄の効果を確認することがで きた。

閾值は $14.5 \mathrm{~mA}$ で, これは電流狭窄の効果が確実に働いた ためと考えられる。また, 発振スペクトルは波長 $812 \mathrm{~nm}$ 付 近において閾值の 3 倍程度まで単一モードが維持され, そ の後新たなモードが現われた。

通常の埋め込み（BH）構造を用いた DFB レーザーの場合 は，4回程度の再成長プロセスを必要とし，また，pn 逆接 合を用いた電流阻止構造により素子の寄生容量が大きくな る欠点がある。一方, 本レーザーは, 形状基板上の 1 回の 選択成長により量子細線 DFB レーザーを実現し, それによ り, プロセスの簡素化が得られている。また再成長プロセ スを含まないため, $\mathrm{Al}$ 組成を含むクラッド層, 例えば $\mathrm{InGaAs} / \mathrm{InGaAlAs}$ 系量子構造の採用により温度特性を改善 することが可能となり, 安価で高性能な量子細線 DFB レー ザーが実現し, 今後のファイバーツーザホーム (FTTH : Fiber to the Home)や車載用通信システムへの応用が可能となる。

本研究の一部は, 文部科学省のナノテクノロジー総合支 援プロジェクトの支援を受けて，（独）産業技術総合研究所 ナノプロセシング施設において実施されました。

(平成 18 年 10 月 11 日受付, 平成 19 年 3 月 9 日再受付)

\section{文献}

(1) M. Walther, E. Kapon, C. Caneau, D. M. Hwang, and L. M. Schiavone : "InGaAs/GaAs strained quantum wire lasers grown by organometallic chemical vapor deposition on nonplanar substrates", Appl. Phys. Lett., Vol.62, No.18, pp.2170-2172 (1993)

(2) X. L. Wang, M. Ogura, and H. Matsuhata : "Temperature Dependent Photoluminescence Investigation of AlGaAs/GaAs Quantum Wires Grown by Flow Rate Modulation Epitaxy", Appl. Phys. Lett., Vol.67, No.24, pp.3629-3631 (1995)

( 3 ) Y. Luo, Y. Nakano, K. Tada, T. Inoue, H. Hosomatsu, and H. Iwaoka : "Purely gain-coupled distributed feedback semiconductor lasers", Appl. Phys. Lett., Vol.56, No.17, pp.1620-1622 (1990)

(4) W. T. Tsang, F. S. Choa, M. C. Wu, Y. K. Chen, R. A. Logan, S. N. G. Chu, A. M. Sergent, P. Magill, K. C. Reichmann, and C. A. Burrus : "Long wavelength InGaAsP/InP distributed feedback lasers grown by chemical beam epitaxy", J. Crystal. Growth 124 pp.716-722 (1992)

(5) K. Takemasa, T. Munakata, M. Kobayashi, H. Wada, and T. Kamijob : "1.3- $\mu \mathrm{m}$ AlGaInAs-AlGaInAs strained multiple-quantum-well lasers with a p-AlInAs electron stopper layer", IEEE Photon. Tech. Lett., Vol.10, pp.495-497 (1998)

(6) H. C. Casey, Jr., D. D. Sell, and M. B. Panish : "Refractive index of AlxGa1-xAs between 1.2 and 1.8eV", Appl. Phys. Lett., Vol.24, No.2, pp.63-65 (1974) 


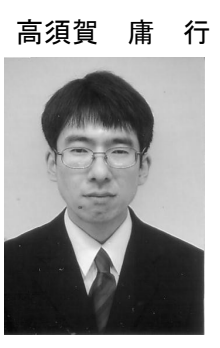

（正員） 2006 年芝浦工業大学大学院工学研究 科博士課程修了。工学博士。現在, 芝浦工業大 学ポスドク研究員および産業技術総合研究所協 力研究員として, 量子細線 DFB レーザーに関す る研究に従事。また 2006 年より地域新生コンソ ーシアム研究開発事業「埼玉オプトプロジェク 卜」に従事。

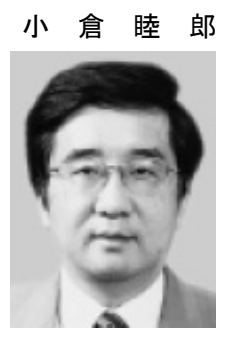

（非会員）1980 年東京大学大学院工学系研究科 電子工学専門課程修了。工学博士。同年電子技 術総合研究所（現産業技術総合研究所）入所。 化合物半導体光・電子デバイスの研究に従事。 1998-2002 年 JST 戦略基礎プロジェクト (Crest), 2004-2009（予）総務省産学官連携先端技術開発 プロジェクト (Scope) 代表。

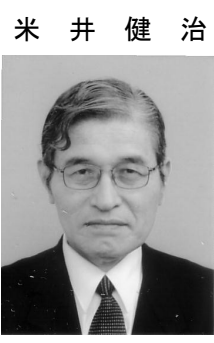

(正員) 1963 年芝浦工業大学工学部電気工学 科卒業。同年同大学工学部電子工学科専任助 手。1 1970 年同専任講師。1 987 年同助教授。1992 年同教授。2007 年 3 月同大学定年退職。現在は （独）産業技術総合研究所客員研究員, 文教大 学教育学部理科専修非常勤講師。芝浦工業大学 在籍中は CCD, 太陽電池セル, In 酸化物透明電 極，金属細線，半導体量子細線およびそれらの 応用の研究に従事。現在は経済産業省新生地域コンソーシアムの研 究に従事。工学博士 (京都大学)。応用物理学会, 電子情報物理学 会, IEEE（SM）各会員。 